\title{
Thrombocytopenia predicts mortality in Chinese hemodialysis patients- an analysis of the China DOPPS
}

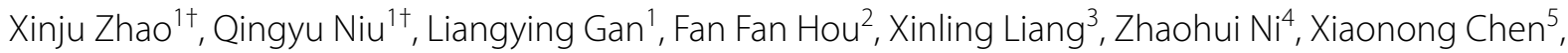
Yuqing Chen ${ }^{6}$, Keith McCullough ${ }^{7}$, Bruce Robinson ${ }^{7}$ and Li Zuo ${ }^{1 *}$

\begin{abstract}
Background: Hemodialysis (HD) patients have a higher mortality rate compared with general population. Our previous study revealed that platelet counts might be a potential risk factor. The role of platelets in HD patients has rarely been studied. The aim of this study is to examine if there is an association of thrombocytopenia (TP) with elevated risk of all-cause mortality and cardiovascular (CV) death in Chinese HD patients.
\end{abstract}

Methods: Data from a prospective cohort study, China Dialysis Outcomes and Practice Patterns Study (DOPPS) 5, were analyzed. Demographic data, comorbidities, platelet counts and other lab data, and death records which extracted from the medical record were analyzed. TP was defined as the platelet count below the lower normal limit $\left(<100^{*} 10^{9} / L\right)$. Associations between platelet counts and all-cause and CV mortality were evaluated using Cox regression models. Stepwise multivariate logistic regression was used to identify the independent associated factors, and subgroup analyses were also carried out.

Results: Of 1369 patients, $11.2 \%$ (154) had TP at enrollment. The all-cause mortality rates were $26.0 \%$ vs. 13.3\% $(p<0.001)$ in patients with and without TP. TP was associated with higher all-cause mortality after adjusted for covariates (HR:1.73,95\%Cl:1.11,2.71), but was not associated with CV death after fully adjusted (HR:1.71,95\%Cl:0.88,3.33). Multivariate logistic regression showed that urine output $<200 \mathrm{ml} /$ day, cerebrovascular disease, hepatitis (B or C), and white blood cells were independent impact factors $(P<0.05)$. Subgroup analysis found that the effect of TP on all-cause mortality was more prominent in patients with diabetes or hypertension, who on dialysis thrice a week, with lower ALB $(<4 \mathrm{~g} / \mathrm{dl})$ or higher hemoglobin, and patients without congestive heart failure, cerebrovascular disease, or hepatitis $(P<0.05)$.

Conclusion: In Chinese HD patients, TP is associated with higher risk of all-cause mortality, but not cardiovascular mortality. Platelet counts may be a useful prognostic marker for clinical outcomes among HD patients, though additional study is needed.

Keywords: Thrombocytopenia, Mortality, Cardiovascular death, Hemodialysis, DOPPS

*Correspondence: zuoli@bjmu.edu.cn

${ }^{+}$Xinju Zhao and Qingyu Niu contributed equally to this work.

${ }^{1}$ Department of Nephrology, Peking University People's Hospital, Unit 10C in Ward Building; 11 Xizhimennan Street, Xicheng District, Beijing 100044, China

Full list of author information is available at the end of the article

\section{Introduction}

Mortality rate was much higher in Hemodialysis (HD) patients than that of individuals in the general population $[1,2]$. According to the global burden of disease study in 2017, end stage kidney disease (ESKD) has become one of the three fastest growing causes of death in the world 
in the past 20 years [3]. Diverse risk factors for death have been identified including older age, arterial hypertension, diabetes mellitus, and ischemic heart disease and so on [4]. Our team's research results suggested that platelet counts might be a potential risk factor (unpublished data). However, few studies have examined the association of platelet count with all-cause and cause-specific mortality in HD patients [5, 6].

Platelet count is a component of a routinely measured clinical assay. Platelet plays a crucial role in the coagulation cascade, clot formation, and wound healing process. Studies suggested that it also serves as biomarker of fibrinogen and inflammation and may be involved in the development of atherosclerosis [7-13]. A U-shaped association between platelet count and increased mortality has been recognized in the general population, women, the elderly, and patients with chronic obstructive pulmonary disease [14-17]. Studies also showed that platelet count was a prognostic indicator in the patients with stroke, and some infectious disease $[18,19]$. In one study about the association about mean platelet volume (MPV) and mortality in incident HD patients, the author also found that lower baseline platelet counts were associated with higher mortality risk across all multivariable models [6]. Thrombocytopenia, defined as abnormally low platelet counts, may have serious consequences, such as increasing the risk of internal and external bleeding, delaying in wound healing and coagulation defects. Furthermore, HD patients might suffer from a prothrombotic adverse drug reaction called Heparin-induced thrombocytopenia (HIT) [20, 21]. However, the prevalence of thrombocytopenia in HD patients is understudied and the relationship between platelet counts and all-cause mortality and cardiovascular (CV) mortality in Chinese HD patients has not been previously explored.

Therefore, using data from China Dialysis Outcomes and Practices Pattern Study (DOPPS), we explored the prevalence of thrombocytopenia in chronic HD patients, and investigated the association between platelet counts and all-cause together with $\mathrm{CV}$ mortality.

\section{Methods}

\section{Study design and subjects}

The DOPPS is an international prospective cohort study of in-center adult HD patients which described in previous published papers [22, 23]. China joined DOPPS in 2011. DOPPS China randomly selected an average of 30 patients from 15 dialysis facilities in each city of Beijing, Shanghai, and Guangzhou. This was described in our previous study [24-26]. There were 1427 patients participated in China DOPPS5 (2012-2015). Of the 1427 patients, 58 patients were excluded from the present analysis as they didn't have the platelet records. Baseline demographic and clinical data were collected at the start of participation in DOPPS5.

The authors confirm that all methods were carried out in accordance with relevant guidelines and regulations.

\section{Patient groups}

Participants were divided into 2 groups according to their baseline platelet counts. Patients with thrombocytopenia (platelet $<100 * 10^{9} / \mathrm{L}$ ) were assigned as TP group, and patients without thrombocytopenia as Non-TP group (platelet $\geq 100 * 10^{9} / \mathrm{L}$ ). The Non-TP could not be further divided into normal $\left(100^{*} 10^{9} / \mathrm{L}-300^{*} 10^{9} / \mathrm{L}\right)$ or above normal (platelet $>300^{*} 10^{9} / \mathrm{L}$ ), since there were few patients who had platelet counts beyond the high-end of normal limits $\left(300^{*} 10^{9} / \mathrm{L}\right)$.

\section{Outcomes}

The primary end-point event was all-cause mortality. The secondary end-point event was the CV mortality during the follow-up period. We have a 'Termination form' to collect patients' death information, including the date, place, primary reason, secondary reason of death. And the reasons of death were divided into several categories (cardiac, vascular, liver disease, infection, gastrointestinal, metabolic, other).

$\mathrm{CV}$ mortality was defined by the primary death records in the dataset. The following diagnosis in primary death records were considered as $\mathrm{CV}$ mortality: atherosclerotic heart disease, cardiac arrest, cardiac arrhythmia, cardiomyopathy, cerebro-vascular accident (including intracranial Hemorrhage), congestive heart failure, hemorrhage from ruptured vascular aneurysm, ischemic brain damage/anoxic encephalopathy, acute myocardial infarction, pulmonary embolus, stroke, and valvular heart disease.

\section{Statistics analysis}

Continuous variables were represented as mean $\pm \mathrm{SD}$ or median (25th, 75th) according to the results of normality test. Categorical variables were expressed as number and percentage. We stratified data by TP and Non-TP groups. Differences in mean or median among groups were evaluated by using analysis of variance or non-parametric test. Categorical data were compared using chi-square test.

Survival curves were produced by the Kaplan-Meier method and estimated by log-rank test. We used Cox proportional hazards models to assess the association of baseline platelet count with all-cause mortality, and CV mortality. All Cox models accounted for facility clustering effects by using the robust sandwich covariance estimate. Survival time for Cox models of all-cause mortality was the time from study entry to the end of study or to death, whichever occurred first. Similar calculation was 
taken for CV mortality. The Non-TP group was taken as the reference group for all analyses. Cox regression models were with 5 incremental levels of covariate adjustment. Model 1: unadjusted; model 2: adjusted for age, gender, body mass index (BMI), vintage; model 3: model 2 variables plus comorbidities (diabetes, coronary artery disease, congestive heart failure, other cardiovascular disease, cerebrovascular disease, hepatitis B and $\mathrm{C}$, cancer (non-skin), peripheral vascular disease, lung disease, hypertension, psychiatric disorder, GI Bleeding, recurrent cellulitis, fracture, neurologic disease); model
4: model 3 plus hemoglobin, albumin, white blood cells, and serum creatinine; model 5: model 4 plus intradialytic weight loss, fistula use, primary kidney disease, standard $\mathrm{kt} / \mathrm{v}$, urine output $<200 \mathrm{ml} /$ day.

We also used stepwise multivariate logistic analysis to identify the impact factors of TP. Odds ratio (OR) and 95\% conference interval (CI) were calculated for each variable.

We performed MI procedure to impute missing data, and continuous and categorical variables were imputed 25 times by fully conditional specification regression

Table 1 Baseline characteristics of HD patients according to the platelet counts

\begin{tabular}{|c|c|c|c|c|}
\hline Variables & All & $\operatorname{TP}(n=154)$ & Non-TP $(n=1215)$ & Pvalue \\
\hline \multicolumn{5}{|l|}{ Demographics } \\
\hline Age (years) & $60(49,71)$ & $62(50,73)$ & $60(49,71)$ & 0.46 \\
\hline Males (\%) & 54.8 & 53.9 & 54.9 & 0.80 \\
\hline Vintage (years) & $2.6(0.9,5.5)$ & $3.87(1.3,7.9)$ & $2.5(0.9,5.2)$ & $<0.01$ \\
\hline BMI & $21.9 \pm 3.7$ & $21.3 \pm 3.4$ & $20.0 \pm 3.7$ & 0.03 \\
\hline Urine output > 200 ml/day (\%) & 32.1 & 17.5 & 33.9 & $<0.01$ \\
\hline Primary kidney diseases (\%) & & & & 0.17 \\
\hline Glomerulonephritis & 39.2 & 43.5 & 38.7 & \\
\hline Diabetic nephropathy & 23.3 & 16.9 & 24.1 & \\
\hline Hypertensive nephropathy & 15.4 & 14.3 & 15.6 & \\
\hline others & 22.1 & 25.3 & 21.7 & \\
\hline \multicolumn{5}{|l|}{ Laboratory tests } \\
\hline $\mathrm{Hgb}(\mathrm{g} / \mathrm{dl})$ & $10.5(9.3,11.7)$ & $10.5(8.9,11.7)$ & $10.6(9.3,11.7)$ & 0.98 \\
\hline Alb (g/dl) & $3.9(3.7,4.2)$ & $3.8(3.6,4.1)$ & $4.0(3.7,4.2)$ & 0.04 \\
\hline White blood cells $\left(10^{\wedge} 9 / L\right)$ & $6.0(4.9,7.3)$ & $4.6(3.8,5.9)$ & $6.1(5.0,7.4)$ & $<0.01$ \\
\hline Creatine (mg/dl) & $10.1(8.0,12.5)$ & $9.6(7.6,11.9)$ & $10.2(8.1,12.5)$ & 0.07 \\
\hline \multicolumn{5}{|l|}{ Dialysis prescription } \\
\hline spKt/N & $1.4(1.2,1.6)$ & $1.4(1.2,1.5)$ & $1.4(1.2,1.6)$ & 0.54 \\
\hline stdKtv_l & $2.0 \pm 0.3$ & $2.1 \pm 0.3$ & $2.0 \pm 0.4$ & 0.27 \\
\hline Dialysis < 3 times /week (\%) & 21.0 & 20.1 & 21.1 & 0.83 \\
\hline Intradialytic weight loss (\%) & $0.04(0.03,0.05)$ & $0.04(0.03,0.05)$ & $0.04(0.03,0.05)$ & 0.17 \\
\hline Fistula use (\%) & 85.0 & 85.7 & 84.9 & 1.00 \\
\hline \multicolumn{5}{|l|}{ Comorbidities (\%) } \\
\hline Diabetes & 27.5 & 22.7 & 28.1 & 0.15 \\
\hline Coronary artery disease & 25.3 & 25.3 & 25.3 & 0.92 \\
\hline Congestive heart failure & 24.3 & 26.6 & 24.0 & 0.49 \\
\hline Other cardiovascular disease & 21.3 & 22.7 & 21.1 & 0.68 \\
\hline Cerebrovascular disease & 14.6 & 20.3 & 13.1 & 0.05 \\
\hline Hypertension & 85.7 & 84.4 & 85.8 & 0.38 \\
\hline Peripheral vascular disease & 9.4 & 9.7 & 9.3 & 0.88 \\
\hline Hepatitis & 13.1 & 27.3 & 11.4 & $<0.01$ \\
\hline Lung disease & 5.1 & 2.0 & 5.4 & 0.17 \\
\hline Cancer (non-skin) & 3.9 & 4.6 & 3.9 & 0.66 \\
\hline Gl Bleeding & 3.9 & 2.3 & 2.5 & 0.26 \\
\hline Liver cirrhosis & 1.3 & 5.5 & 0.8 & $<0.01$ \\
\hline All-cause death & 14.7 & 26.0 & 13.3 & $<0.01$ \\
\hline Cardiac/Vascular death & 7.5 & 11.7 & 6.9 & 0.05 \\
\hline
\end{tabular}

Note: $B M I$ body mass index, $\mathrm{Hgb}$ hemoglobin, Alb albumin, spKt/N single-pooled Kt/N, stdKt/N standardized Kt/V 
and logistic regression, respectively. The imputed data sets were analyzed using the MI Analyze procedure in SAS/STAT 9.4. Percentages of missing for most variables were $<10 \%$, except for single-pooled Kt/V (36.2\%). $P$ value $<0.05$ was considered as statistically significant. All statistical analyses were performed with SAS, version 9.4 (SAS institute, Cary, NC; USA).

\section{Results}

\section{Demographic data and clinical characteristics}

There were 1369 patients had baseline platelet counts. In the study cohort, male patients were $54.8 \%$. The median age was $60(49,71)$ years old and median dialysis vintage was $2.6(0.9,5.5)$ years. The median follow-up time of this study was $1.9(1.2-2.1)$ years. The median platelet count was $160 * 10^{9}(123,204)$. The baseline characteristics of HD patients was shown in Table 1. The prevalence of TP was $11.2 \%$. Patients with TP tended to be with longer dialysis vintage, lower BMI, less likely had residual renal function (higher proportion of patients with urine output $<200 \mathrm{ml} /$ day), lower Alb, lower white blood cells, and more likely having hepatitis and liver cirrhosis (Table 1).

\section{Associations between platelet counts and outcomes}

Among 1369 included patients, 201(14.7\%) died and 102 (7.5\%) died from CV disease. The median platelet count in the alive group was $163^{*} 10^{9} / \mathrm{L}$ which was higher than that in the dead group which was $147^{*} 10^{9} / \mathrm{L}$. The distribution of primary causes of death was shown in Table 2. According to the results of Kaplan-Meier analysis, patients with TP had significant higher risk of all-cause mortality and $C V$ related deaths (log-rank test, $P<0.01$ and 0.03 respectively, Fig. $1 \mathrm{~A}$ and B). In fully adjusted Cox model, TP were associated with higher all-cause mortality after adjusted for covariates (HR:1.73,95\%CI:1.11,2.71). However, TP was not associated with $\mathrm{CV}$ deaths after full

Table 2 The distribution of primary causes of death

\begin{tabular}{llll}
\hline Causes of deaths $(\mathbf{n}, \%)$ & All $(\boldsymbol{n}=\mathbf{2 0 1})$ & TP $(\boldsymbol{n}=\mathbf{4 0})$ & Non-TP $(\boldsymbol{n}=\mathbf{1 6 1})$ \\
\hline CardiacNascular & $102(50.8)$ & $18(45)$ & $84(52.2)$ \\
Liver Disease & $2(1.0)$ & $1(2.5)$ & $1(0.6)$ \\
Infection & $33(16.4)$ & $9(22.5)$ & $24(14.9)$ \\
Gastrointestinal & $8(3.9)$ & $1(2.5)$ & $7(4.3)$ \\
Metabolic & $6(3.0)$ & 0 & $6(3.7)$ \\
Other & $19(9.5)$ & $3(7.5)$ & $16(9.9)$ \\
Unknown & $31(15.4)$ & $8(20)$ & $23(14.3)$ \\
\hline
\end{tabular}

Note: Patients whose cause of death was missing was categorized into 'unknown' group. The OTHER cause including Bone marrow depression; Cachexia/failure to thrive; Malignant disease, patient ever on Immunosuppressive therapy; Malignant disease; Dementia, incl. Dialysis dementia, Alzheimer's; Seizures; Chronic obstructive lung disease (COPD); Complications of surgery; Air embolism; Withdrawal from dialysis/uremia; Accident related to treatment; Accident unrelated to treatment; Suicide; Drug overdose (street drugs); Drug overdose; Multiple organ failure; Other cause of death adjustment at the statistical significance level of 0.05 (HR:1.71,95\%CI:0.88,3.33, Fig. 2).

\section{Impact factors of thrombocytopenia}

Stepwise multivariate logistic regression showed that urine output $<200 \mathrm{ml} /$ day (OR: $2.01 ; 95 \%$ CI 1.29-3.15; $P<0.01$ ), cerebral disease (OR: 1.63 ; 95\% CI 1.00-2.66; $\mathrm{P}=0.03$ ), hepatitis (B or C, OR: 2.43 ; 95\% CI 1.58-3.75; $\mathrm{P}<0.01)$ were independent risk factor of TP. However, white blood cells were negatively associated with TP (OR: 0.70; 95\% CI 0.62-0.78; P < 0.01, Table 3).

\section{Subgroup analysis}

Subgroup analysis found that the effect of TP on all-cause mortality was more prominent in patients with diabetes or hypertension, who on dialysis thrice a week, with lower ALB $(<4 \mathrm{~g} / \mathrm{dl})$ or higher hemoglobin, and those who without congestive heart failure, or cerebrovascular disease, hepatitis $(P<0.05$, Fig. 3$)$.

There seemed to have a trend but not of significant difference in patients with other cardiovascular disease $(p=0.05)$, and with dialysis vintage less than 3 years $(P=0.06)$.

There were no significant differences for patients who were younger or older (cutoff value: 60 years old), female or male, with or without adequate dialysis (standardized $\mathrm{Kt} / \mathrm{V}, \mathrm{stdKtV}>2.0$, with or without urine output $<200 \mathrm{ml}$, and using fistula or catheter.

\section{Discussion}

In this large perspective cohort study of HD patients, we found that TP was positively associated with all-cause mortality. This finding is in line with similar observations made in incident dialysis patients [6] and patients with acute myocardial infarction/ acute coronary syndrome treated with percutaneous coronary intervention and acute ischemic stroke treated with mechanical thrombectomy [18]. The association between TP and CV mortality had a trend yet was not statistically significant after full adjustments. To our knowledge, this is the first study focused on investigating the association between platelet count and mortality in Chinese dialysis population. These findings expand upon our prior study suggesting TP might serve as a risk factor for all-cause mortality.

Like in the general and some other population, the previously mentioned retrospective study with large sample size found a U-shaped association in incident HD patients between platelet count and mortality [6]. However, the association between higher baseline platelet counts and death risk were attenuated by casemixed adjustments [6] which was in line with another previously published research [5]. In that study, using 


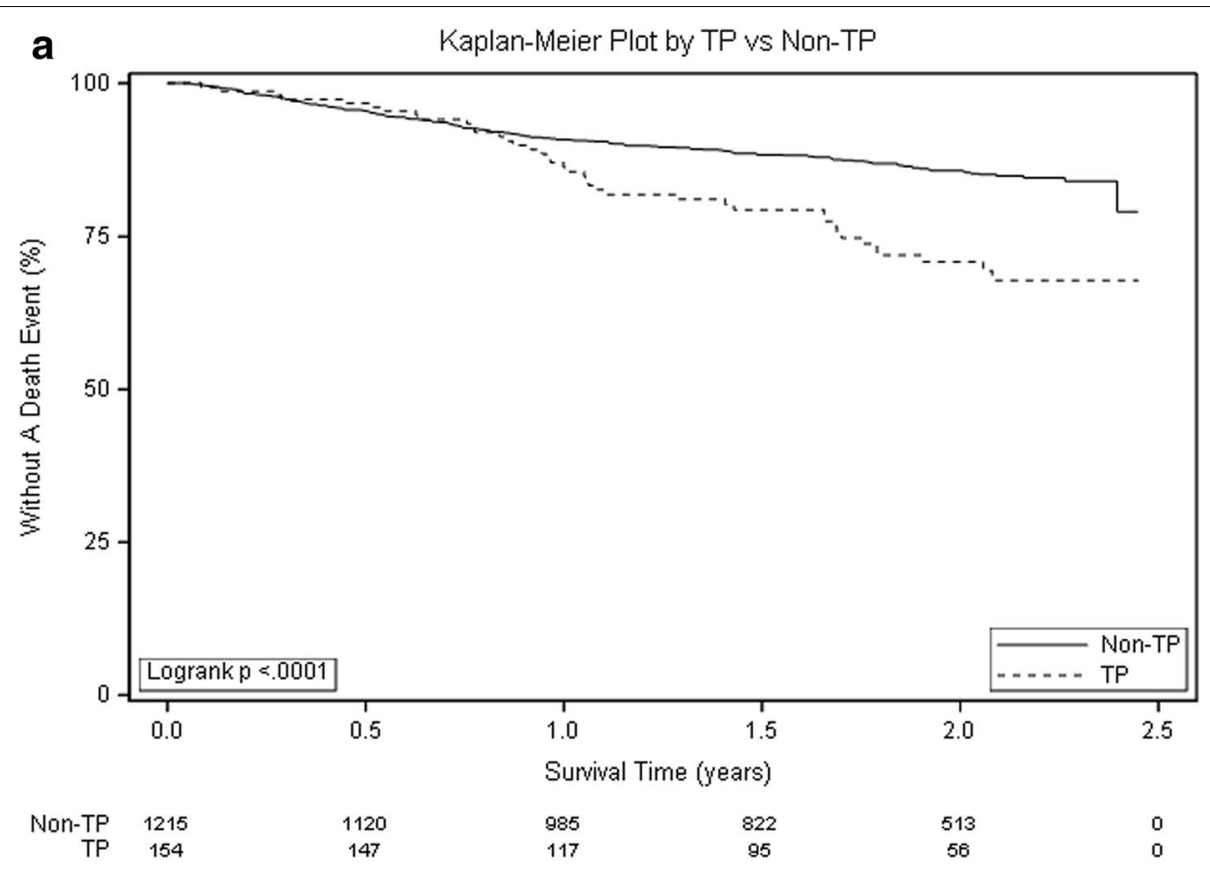

b Kaplan-Meier Plot by TP vs Non-TP

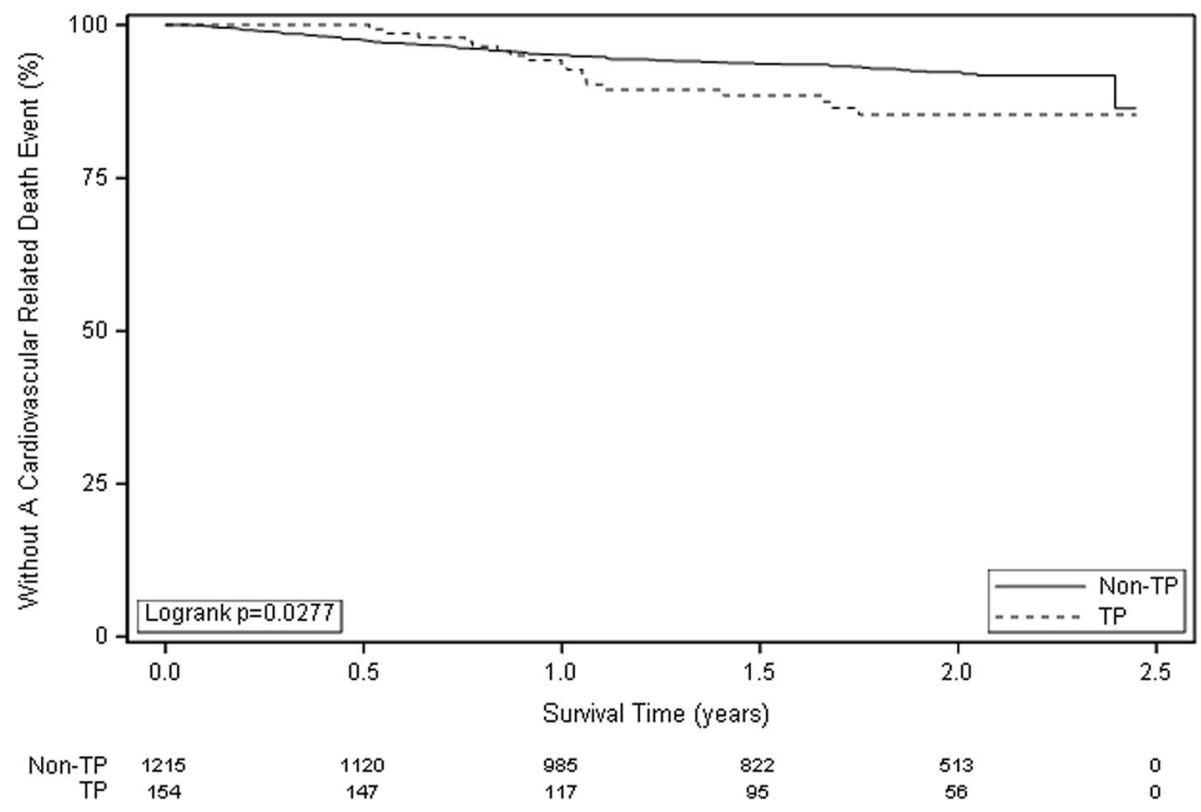

Fig. 1 The Kaplan-Meier curves for TP and Non-TP groups in HD patients. A Survival curves of all-cause mortality; B Survival curves of CV mortality between two groups. Abbreviations: HD hemodialysis; TP thrombocytopenia; Non-TP without thrombocytopenia

national DaVita maintenance hemodialysis patient cohort, the author suggested that high platelet count might act as a link between renal cachexia and cardiovascular mortality [5]. In our study, we could not explore if high-platelet counts (thrombocytosis) will be associated with mortality in our cohort as limited by the small number of patients with platelet count higher than the upper limit.

The causative link between TP and increased mortality risk is not entirely clear. TP related to hemorrhagic complications which could be one plausible explanation. Administration of heparin in the dialysis process might 


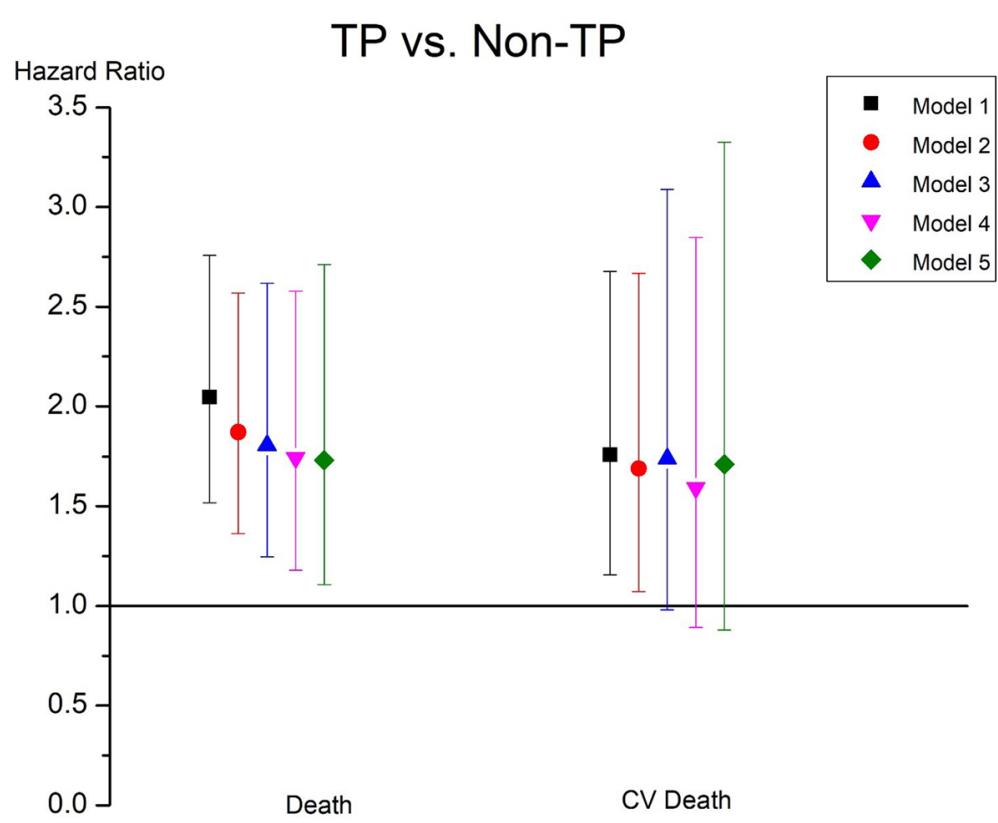

Fig. 2 Associations between the platelet counts and all-cause mortality and CV mortality in different Cox regression models. Notes: Model 1: unadjusted; model 2: adjusted for age, gender, BMI, vintage; model 3: model 2 variables plus comorbidities (diabetes, coronary artery disease, congestive heart failure, other cardiovascular disease, cerebrovascular disease, hepatitis B and C, cancer (non-skin), peripheral vascular disease, lung disease, hypertension, psychiatric disorder, Gl Bleeding, recurrent cellulitis, fracture, neurologic disease).; model 4: model 3 plus hemoglobin, albumin, white blood cells, and serum creatinine; model 5: model 4 plus Intradialytic weight loss, fistula use, primary kidney disease, standard kt/v, urine output < $200 \mathrm{ml} / \mathrm{d}$. Abbreviations: TP thrombocytopenia; Non-TP without thrombocytopenia

lead to an autoantibody-mediated destruction of platelets, called HIT $[20,21]$. Some HIT patients may show unusual clinical consequences, such as thrombocytopenia, disseminated intravascular coagulation and microvascular thrombosis. Several studies showed that HD patients with HIT were at a higher risk of cardiovascular mortality and arteriovenous fistula thrombosis than patients without HIT [20, 21, 27]. Some studies showed that in immune thrombocytopenic purpura and stoke patients, elevated levels of platelet microparticles (PMP) might be associated with an increased thrombogenic risk hence mortality risk [28-30]. Whether PMP has any influence on adverse outcomes in HD patients is worthy of further study.

Table 3 Stepwise multivariate logistic regression for impact factors of thrombocytopenia

\begin{tabular}{llll}
\hline Variables & Odds ratios & $\mathbf{9 5 \%} \mathbf{C l}$ & P value \\
\hline Urine output < 200 ml/day (yes vs. no) & 2.01 & $1.29-3.15$ & $<0.01$ \\
Cerebral disease (yes vs. no) & 1.63 & $1.00-2.66$ & 0.03 \\
Hepatitis (B or C) (yes vs. no) & 2.43 & $1.58-3.75<0.01$ \\
White blood cells & 0.70 & $0.62-0.78<0.01$ \\
\hline
\end{tabular}

Studies in healthy populations reported contradict results about the association between platelet concentrations and function with cardiovascular mortality [31, 32]. In a cohort of incident peritoneal dialysis patients, researchers found higher platelet counts and plateletcrit might be associated with higher risk for cardiovascular mortality [33]. In our study, we found the trend that TP might be associated with cardiovascular mortality but was not of statistically significance. However, the number of cardiovascular events was small in our cohort.

Trying to decipher the underlying pathophysiology of TP is challenging. Not surprisingly, some comorbidities, such as cerebral disease and hepatitis are positively associated with higher risk for TP. Liver cirrhosis is one of the major causes of low platelet count in clinical settings. We did have a higher proportion of liver cirrhosis in TP group than in Non-TP group patients. However, there were all together 18 patients (1.3\%) with liver cirrhosis in this cohort which should not be the main underlying cause. Auto-immune diseases and bone marrow diseases might also affect platelet counts. In primary causes of ESKD, these should be categorized as other causes which had similar proportion in both TP and Non-TP patients. However, we could not 


\begin{tabular}{|c|c|c|c|c|}
\hline \multicolumn{5}{|c|}{ Hazard Ratio } \\
\hline Subgroup & No. of Patients (\%) & & $\mathrm{HR}(95 \% \mathrm{Cl})$ & P-Value \\
\hline $\begin{array}{l}\text { StdKtV_I } \\
<2.0- \\
>=2.0\end{array}$ & $\begin{array}{l}260(19.0) \\
443(32.4)\end{array}$ & $H=-1$ & $\begin{array}{l}1.69(0.68,4.21) \\
1.80(0.94,3.43)\end{array}$ & $\begin{array}{l}0.26 \\
0.08\end{array}$ \\
\hline $\begin{array}{l}\text { Gender } \\
\text { Male } \\
\text { Female }\end{array}$ & $\begin{array}{l}750(54.8) \\
617(45.1)\end{array}$ & $\stackrel{\longrightarrow}{\longmapsto}$ & $\begin{array}{l}1.38(0.41,4.68) \\
2.08(0.96,4.52)\end{array}$ & $\begin{array}{l}0.60 \\
0.06\end{array}$ \\
\hline $\begin{array}{l}\text { Age } \\
>=60 \\
>=60\end{array}$ & $\begin{array}{l}665(48.6) \\
700(51.1)\end{array}$ & $\stackrel{1}{-\longrightarrow}$ & $\begin{array}{l}1.91(0.69,5.29) \\
1.59(0.68,3.72)\end{array}$ & $\begin{array}{l}0.21 \\
0.28\end{array}$ \\
\hline $\begin{array}{l}\text { Type of vascular access } \\
\text { Fistula } \\
\text { Catheter }\end{array}$ & $\begin{array}{l}1163(85.0) \\
195(14.2)\end{array}$ & $\longmapsto$ & $\begin{array}{l}2.19(0.76,6.32) \\
2.38(0.35,16.21)\end{array}$ & $\begin{array}{l}0.15 \\
0.38\end{array}$ \\
\hline $\begin{array}{l}\text { Diabetes } \\
\text { Yes } \\
\text { No }\end{array}$ & $\begin{array}{l}377(27.5) \\
978(71.4)\end{array}$ & $\stackrel{\longmapsto}{\mapsto-1}$ & $\begin{array}{l}2.57(1.20,5.54) \\
1.55(0.89,2.69)\end{array}$ & $\begin{array}{l}0.02 \\
0.12\end{array}$ \\
\hline $\begin{array}{l}\text { Dialyze } \geq 3 \text { times/w } \\
\text { Yes } \\
\text { No }\end{array}$ & $\begin{array}{l}1077(78.7) \\
288(21.0)\end{array}$ & & $\begin{array}{l}2.07(1.22,3.50) \\
0.40(0.08,1.92)\end{array}$ & $\begin{array}{l}0.01 \\
0.25\end{array}$ \\
\hline $\begin{array}{l}\text { Congestive heart failure } \\
\text { Yes } \\
\text { No }\end{array}$ & $\begin{array}{l}333(24.3) \\
1031(75.3)\end{array}$ & $r$ & $\begin{array}{l}1.27(0.46,3.54) \\
1.88(1.07,3.30)\end{array}$ & $\begin{array}{l}0.65 \\
0.03\end{array}$ \\
\hline$\underset{\substack{<4 \\
>=4}}{\text { Albumin }}(\mathrm{g} / \mathrm{dL})$ & $\begin{array}{l}682(49.8) \\
577(42.1)\end{array}$ & $\stackrel{1}{1 \oplus-1}$ & $\begin{array}{l}2.15(1.22,3.80) \\
1.11(0.40,3.13)\end{array}$ & $\begin{array}{l}0.01 \\
0.84\end{array}$ \\
\hline $\begin{array}{l}\text { Hemoglobin }(g / d L) \\
>9=9\end{array}$ & $\begin{array}{l}274(20.0) \\
109(80.0)\end{array}$ & $\stackrel{H}{H}$ & $\begin{array}{l}1.77(0.66,4.73) \\
1.79(1.08,2.96)\end{array}$ & $\begin{array}{l}0.26 \\
0.02\end{array}$ \\
\hline $\begin{array}{l}\text { Other cardiovascular disease } \\
\text { Yes } \\
\text { No }\end{array}$ & $\begin{array}{l}292(21.3) \\
1075(78.5)\end{array}$ & $r=-1$ & $\begin{array}{l}0.75(0.13,4.34) \\
1.73(0.99,3.00)\end{array}$ & $\begin{array}{l}0.74 \\
0.05\end{array}$ \\
\hline $\begin{array}{l}\text { Cerebrovascular Disease } \\
\text { Yes } \\
\text { No }\end{array}$ & $\begin{array}{c}200(14.6) \\
1163(85.0)\end{array}$ & $H$ & $\begin{array}{l}1.15(0.38,3.48) \\
1.85(1.11,3.08)\end{array}$ & $\begin{array}{l}0.81 \\
0.02\end{array}$ \\
\hline $\begin{array}{l}\text { Hypertension } \\
\text { Yes } \\
\text { No }\end{array}$ & $\begin{array}{l}1173(85.7) \\
180(13.2)\end{array}$ & $10-1$ & $\begin{array}{l}1.67(1.01,2.77) \\
1.95(0.45,8.41)\end{array}$ & $\begin{array}{l}0.05 \\
0.37\end{array}$ \\
\hline $\begin{array}{l}\text { Urine output } \\
>=200 \\
<200\end{array}$ & $\begin{array}{l}439 \text { (32.1) } \\
889(64.9)\end{array}$ & $\stackrel{H}{H-1}$ & $\begin{array}{l}1.88(0.52,6.81) \\
1.67(0.94,2.99)\end{array}$ & $\begin{array}{l}0.34 \\
0.08\end{array}$ \\
\hline $\begin{array}{l}\text { Vintage } \\
<3 \\
>=3\end{array}$ & $\begin{array}{l}730(53.3) \\
610(44.6)\end{array}$ & $\stackrel{1}{H-1}$ & $\begin{array}{l}1.89(0.98,3.65) \\
1.57(0.87,2.84)\end{array}$ & $\begin{array}{l}0.06 \\
0.13\end{array}$ \\
\hline $\begin{array}{l}\text { Heptitis B or C } \\
\text { Yes } \\
\text { No }\end{array}$ & $\begin{array}{l}180(13.2) \\
1186(86.6)\end{array}$ & +1 & $\begin{array}{l}0.36(0.09,1.49) \\
2.03(1.25,3.31)\end{array}$ & $\begin{array}{l}0.16 \\
0.00\end{array}$ \\
\hline & & 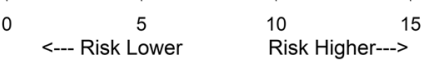 & & \\
\hline
\end{tabular}

identify these diseases in patients' comorbidities. We found that white blood cells were negatively associated with TP. Both of platelet and white blood cell might be influenced by the bone marrow status. Why urine output $<200 \mathrm{ml} /$ day was associated with higher risk of TP in our patients is not fully understand. As noted, drugs may influence blood platelet counts, however, we could not do further analysis due to the limited data about drug usage. 
Our study has several limitations. Firstly, this is an observational study which might has inherent shortcomings such as selection bias and confounding factors. Secondly, the study was lack of additional measurements of platelet activity and function, such as MPV and PMP. Thirdly, we could not identify the proportion of patients who had auto-immune diseases and bone marrow diseases which might have influence on platelet counts and mortality. Finally, we could not do analysis related with drug usage. Nevertheless, we believe these factors should not affect our main findings.

\section{Conclusion}

In this prospective cohort study, thrombocytopenia was associated with an increased risk of all-cause mortality. The association was not attenuated by adjusting for several potential confounding factors. Platelet counts may be used as early available outcome predictors among HD patients.

\section{Abbreviations}

HD: Hemodialysis; TP: Thrombocytopenia; CV: Cardiovascular; DOPPS: Dialysis Outcomes and Practice Patterns Study; ESKD: End stage kidney disease; MPV: Mean platelet volume; HIT: Heparin-induced thrombocytopenia; BMI: Body mass index; stdKt/N: Standardized Kt/N; OR: Odds ratio; Cl: Conference interval; PMP: Platelet microparticles.
\end{abstract}

\section{Acknowledgments}

The Dialysis Outcomes and Practice Patterns Study (DOPPS) Program in China is supported by Vifor Fresenius Renal Pharma, Sanofi Renal, Nipro Trading (Shanghai) Co., Ltd., 3SBio Inc., B.Braun, CEMMA MEDICAL. All of them had no role in study design; collection, analysis, and interpretation of data; writing the report; and all support was provided without restrictions on publications.

\section{Authors' contributions}

$X Z$, LZ contributed to conception and design of the research; XZ, QN analyzed the data; $X Z, Q N, L Z$ interpreted the results of experiments; $X Z, Q N$ wrote the drafted manuscript; LG, FFH, XL, ZN, XC, YC, LZ, KM, BR edited and revised the manuscript; $L Z$ have primary responsibility for the final content. All authors have read and approved the manuscript.

\section{Funding}

This article was supported by National Natural Science foundation of China, and the grant recipient is Li ZUO, grant number is 81870524 .

\section{Availability of data and materials}

The data used of this study are available from the corresponding author on reasonable request.

\section{Declarations}

Ethics approval and consent to participate

The study was approved by the Ethics Committee of Peking University People's Hospital (ethical approval number: 2018PHB028-01). All patients signed the written informed consent.

\section{Consent for publication}

Not Applicable.

\section{Competing interests}

The authors declare that they have no competing interests.

\section{Author details}

${ }^{1}$ Department of Nephrology, Peking University People's Hospital, Unit 10C in Ward Building; 11 Xizhimennan Street, Xicheng District, Beijing 100044, China. ${ }^{2}$ Division of Nephrology, Nanfang Hospital, Southern Medical University, National Clinical Research Center of Kidney Disease, State Key Laboratory of Organ Failure Research, 1838 North Guangzhou Avenue, Guangzhou, China. ${ }^{3}$ Division of Nephrology, Guangdong Provincial People's Hospital, Guangdong Academy of Medical Sciences, Guangzhou, China. ${ }^{4}$ Department of Nephrology, Renji Hospital, School of Medicine, Shanghai Jiaotong University, Shanghai, China. ${ }^{5}$ Division of Nephrology, Ruijin Hospital, School of Medicine, Shanghai Jiaotong University, Shanghai, China. ${ }^{6}$ Renal Division, Peking University First Hospital, Beijing, China. ${ }^{7}$ Arbor Research Collaborative for Health, Ann Arbor, MI, USA.

Received: 11 June 2021 Accepted: 22 October 2021

Published online: 03 January 2022

\section{References}

1. Hall YN, Sugihara JG, Go AS, et al. Differential mortality and transplantation rates among Asians and Pacific islanders with ESRD. J Am Soc Nephrol. 2005;16(12):3711-20.

2. Hallan SI, Matsushita K, Sang Y, et al. Age and association of kidney measures with mortality and end-stage renal disease. JAMA. 2012;308(22):2349-60.

3. GBD 2017 Disease and Injury Incidence and Prevalence Collaborators. Global, regional, and national incidence, prevalence, and years lived with disability for 354 diseases and injuries for 195 countries and territories, 1990-2017: a systematic analysis for the Global Burden of Disease Study 2017. Lancet. 2018;392(10159):1789-858. https://doi.org/10.1016/ S0140-6736(18)32279-7. Epub 2018 Nov 8. Erratum in: Lancet. 2019 Jun 22;393(10190):e44. PMID: 30496104; PMCID: PMC6227754.

4. Ma L, Zhao S. Risk factors for mortality in patients undergoing hemodialysis: a systematic review and meta-analysis. Int J Cardiol. 2017;238:151-8.

5. Molnar MZ, Streja E, Kovesdy CP, et al. High platelet count as a link between renal cachexia and cardiovascular mortality in end-stage renal disease patients. Am J Clin Nutr. 2011;94(3):945-54.

6. Kim S, Molnar MZ, Fonarow GC, et al. Mean platelet volume and mortality risk in a national incident hemodialysis cohort. Int J Cardiol. 2016;220:862-70.

7. Davì G, Patrono C. Platelet activation and atherothrombosis. N Engl J Med. 2007;357(24):2482-94.

8. Stokes KY, Granger DN. Platelets: a critical link between inflammation and microvascular dysfunction. J Physiol. 2012;590(5):1023-34.

9. Iba T, Levy JH. Inflammation and thrombosis: roles of neutrophils, platelets and endothelial cells and their interactions in thrombus formation during sepsis. J Thromb Haemost. 2018;16(2):231-41.

10. Koupenova M, Clancy L, Corkrey HA, et al. Circulating platelets as mediators of immunity, inflammation, and thrombosis. Circ Res. 2018;122(2):337-51.

11. Thomas MR, Storey RF. The role of platelets in inflammation. Thromb Haemost. 2015;114(3):449-58.

12. Vogel S, Thein SL. Platelets at the crossroads of thrombosis, inflammation and haemolysis. Br J Haematol. 2018;180(5):761-7.

13. Burkard P, Vögtle T, Nieswandt B. Platelets in Thrombo-inflammation: concepts, mechanisms, and therapeutic strategies for ischemic stroke. Hamostaseologie. 2020;40(2):153-64.

14. Kabat GC, Kim MY, Verma AK, et al. Platelet count and total and causespecific mortality in the Women's Health Initiative. Ann Epidemiol. 2017;27(4):274-80.

15. Fawzy A, Anderson JA, Cowans NJ, et al. Association of platelet count with all-cause mortality and risk of cardiovascular and respiratory morbidity in stable COPD. Respir Res. 2019;20(1):86.

16. Vinholt PJ, Hvas AM, Frederiksen $\mathrm{H}$, et al. Platelet count is associated with cardiovascular disease, cancer and mortality: a population-based cohort study. Thromb Res. 2016;148:136-42. 
17. Tsai MT, Chen YT, Lin CH, et al. U-shaped mortality curve associated with platelet count among older people: a community-based cohort study. Blood. 2015;126(13):1633-5.

18. Mönch S, Boeckh-Behrens T, Kreiser K, et al. Thrombocytopenia and declines in platelet counts: predictors of mortality and outcome after mechanical thrombectomy. J Neurol. 2019;266(7):1588-95.

19. Chen $Y$, Yang $Y$, Cheng J, et al. Platelet count and mortality of H7N9 infected patients in Guangdong, China. Platelets. 2020;31(2):268-71.

20. Lazrak HH, René É, Elftouh N, et al. Safety of low-molecular-weight heparin compared to unfractionated heparin in hemodialysis: a systematic review and meta-analysis. BMC Nephrol. 2017;18(1):187.

21. Syed S, Reilly RF. Heparin-induced thrombocytopenia: a renal perspective. Nat Rev Nephrol. 2009;5(9):501-11.

22. Pisoni RL, Gillespie BW, Dickinson DM, et al. The Dialysis outcomes and practice patterns study (DOPPS): design, data elements, and methodology. Am J Kidney Dis. 2004;44(5 Suppl 2):7-15.

23. Port FK, Eknoyan G. The Dialysis outcomes and practice patterns study (DOPPS) and the kidney disease outcomes quality initiative (K/DOQI): a cooperative initiative to improve outcomes for hemodialysis patients worldwide. Am J Kidney Dis. 2004;44(5 Suppl 2):1-6.

24. Zhao X, Niu Q, Gan L, et al. Baseline data report of the China Dialysis outcomes and practice patterns study (DOPPS). Sci Rep. 2021;11(1):873.

25. Niu Q, Zhao X, Gan L, et al. Physical function and clinical outcomes in hemodialysis patients: China Dialysis outcomes and practice patterns study. Kidney Dis (Basel). 2021;7(4):315-22.

26. Zhao X, Niu Q, Gan L, et al. Blood flow rate: An independent risk factor of mortality in Chinese hemodialysis patients. Semin Dial. 2021. https:// doi.org/10.1111/sdi.13023. Epub ahead of print. PMID: 34550635.

27. Pena de la Vega L, Miller RS, Benda MM, et al. Association of heparindependent antibodies and adverse outcomes in hemodialysis patients: a population-based study. Mayo Clin Proc. 2005;80(8):995-1000.

28. Boilard E, Duchez AC, Brisson A. The diversity of platelet microparticles. Curr Opin Hematol. 2015;22(5):437-44.

29. Zhao H, Lian $Y$, Zhang $H$, et al. Ischemic stroke associated with immune thrombocytopenia. J Thromb Thrombolysis. 2015;40(2):156-60.

30. Lee YJ, Jy W, Horstman LL, et al. Elevated platelet microparticles in transient ischemic attacks, lacunar infarcts, and multiinfarct dementias. Thromb Res. 1993;72(4):295-304.

31. Thaulow E, Erikssen J, Sandvik L, et al. Blood platelet count and function are related to total and cardiovascular death in apparently healthy men. Circulation. 1991;84(2):613-7.

32. Pizzi C, De Stavola BL, Meade TW. Long-term association of routine blood count (coulter) variables on fatal coronary heart disease: 30-year results from the first prospective Northwick Park heart study (NPHS-I). Int J Epidemiol. 2010;39(1):256-65.

33. Peng F, Li Z, Yi C, et al. Platelet index levels and cardiovascular mortality in incident peritoneal dialysis patients: a cohort study. Platelets. 2017:28(6):576-84.

\section{Publisher's Note}

Springer Nature remains neutral with regard to jurisdictional claims in published maps and institutional affiliations.

Ready to submit your research? Choose BMC and benefit from:

- fast, convenient online submission

- thorough peer review by experienced researchers in your field

- rapid publication on acceptance

- support for research data, including large and complex data types

- gold Open Access which fosters wider collaboration and increased citations

- maximum visibility for your research: over $100 \mathrm{M}$ website views per year

At BMC, research is always in progress.

Learn more biomedcentral.com/submissions 